\title{
Return to play after hip arthroscopy among tennis players: outcomes with minimum five-year follow-up
}

David R. Maldonado ${ }^{1}$, Mitchell J. Yelton ${ }^{1}$, Philip J. Rosinsky ${ }^{1}$, Jacob Shapira', Mitchell B. Meghpara ${ }^{1,2}$, Ajay C. Lall ${ }^{1,3}$ and Benjamin G. Domb $b^{1,3^{*}}$

\begin{abstract}
Background: Playing tennis is associated with various movements that can lead to labral injuries and may require arthroscopic surgery. While hip arthroscopies have demonstrated good outcomes in athletes, there is limited literature reporting patient reported outcomes (PROs) and return to sport (RTS) in competitive or recreational tennis players after arthroscopic hip surgery. Therefore, the purpose of the present study was to (1) report minimum fiveyear PROs and RTS in tennis players who underwent arthroscopic hip surgery and (2) compare outcomes between recreational and competitive tennis players.

Methods: Data for patients who underwent hip arthroscopy surgery in the setting of femoroacetabular impingement and labral tears between March 2009 and January 2014 and who played tennis within one-year of surgery were retrospectively reviewed. Patients with preoperative and minimum five-year postoperative scores for the following PROs were included: modified Harris Hip Score (mHHS), Non-Arthritic Hip Score (NAHS), Hip Outcome Score-Sport Specific Subscale (HOS-SSS), and visual analog scale (VAS) for pain. Patient Acceptable Symptomatic State (PASS) and Minimal Clinically Important Difference (MCID) for mHHS and HOS-SSS were calculated.

Results: Of 28 patients, 31 hips met all inclusion and exclusion criteria of which 28 (90.3\%) had minimum 5-year follow-up (mean: $72.8 \pm 13.9$ months). There were 3 professional, 3 collegiate, 2 high school, 2 organized amateur, and 18 recreational level tennis players. All PROs significantly improved at latest follow-up: $\mathrm{mHHS}$ from 67.0 to 86.7 $(P<0.001)$, NAHS from 65.9 to 87.2 $(P<0.001)$, HOS-SSS from 50.0 to $77.9(P=0.009)$, and VAS from 5.4 to 1.8 $(P<0.001)$. There was a $75.0 \%$ RTS rate. Additionally, 66.7\% of patients achieved MCID and $83.3 \%$ achieved PASS for $\mathrm{mHHS}$, and $63.6 \%$ achieved MCID and 58.3\% achieved PASS for HOS-SSS.

(Continued on next page)
\end{abstract}

\footnotetext{
* Correspondence: DrDomb@americanhipinstitute.org

This study was performed at the American Hip Institute Research

Foundation.

'American Hip Institute Research Foundation, Des Plaines, IL 60018, USA

${ }^{3}$ American Hip Institute, 999 E Touhy Ave, Suite 450, Des Plaines, IL 60018,

USA

Full list of author information is available at the end of the article
}

(c) The Author(s). 2020 Open Access This article is licensed under a Creative Commons Attribution 4.0 International License, which permits use, sharing, adaptation, distribution and reproduction in any medium or format, as long as you give appropriate credit to the original author(s) and the source, provide a link to the Creative Commons licence, and indicate if changes were made. The images or other third party material in this article are included in the article's Creative Commons licence, unless indicated otherwise in a credit line to the material. If material is not included in the article's Creative Commons licence and your intended use is not permitted by statutory regulation or exceeds the permitted use, you will need to obtain permission directly from the copyright holder. To view a copy of this licence, visit http://creativecommons.org/licenses/by/4.0/. The Creative Commons Public Domain Dedication waiver (http://creativecommons.org/publicdomain/zero/1.0/) applies to the data made available in this article, unless otherwise stated in a credit line to the data. 


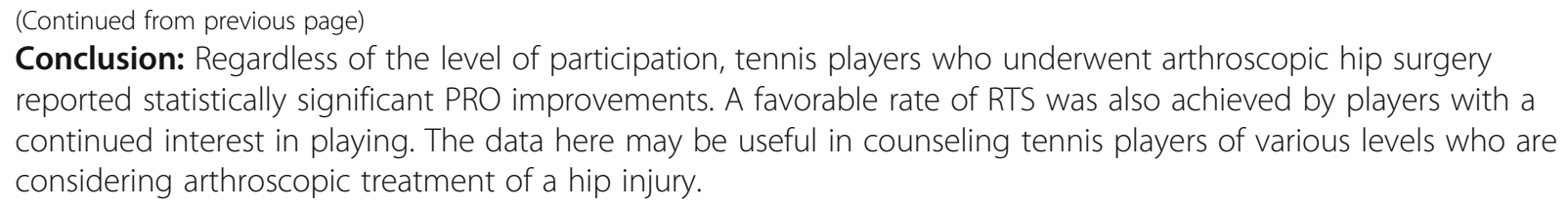

Keywords: Hip arthroscopy, Return to sport, Patient-reported outcomes

\section{Background}

The popularity of tennis has increased in recent years, becoming one of the most popular sports across the world, with over 75 million participants worldwide [1]. According to the Tennis Industry Association (TIA), almost 18 million Americans play tennis and another 14 million show interest in the sport. Playing tennis is associated with rotational stresses, cutting movements, and repetitive loading, which can lead to labral injuries [2]. Injuries of the hip joint account for $6 \%$ of sport injuries [2]. For tennis specifically, hip joint injuries may account for up to $27 \%$ of the sport's injuries [2]. Surgical treatments for hip injuries have been revolutionized with hip arthroscopy, which have demonstrated good outcomes in athletes [3-7]. Byrd and Jones reported successful long-term outcomes after arthroscopic management of femoroacetabular impingement (FAI) in athletes [8]. Weber et al. examined return to play in professional and recreational athletes of a variety of sports following hip arthroscopy for treatment of FAI. They reported that recreational and professional athletes returned to their sport at similar rates and had comparable satisfaction and patient reported outcomes (PROs) [9]. In a systematic review, $87 \%$ of athletes with symptomatic FAI returned to their respective sport after hip arthroscopy, and $82 \%$ returned to the same level of play prior to the onset of their symptoms [10]. To our knowledge, there is limited data in the literature reporting PROs and return to play in competitive or recreational tennis players after arthroscopic hip surgery. The purpose of the present study was to (1) report minimum five-year PROs and rate of return to sport (RTS) in tennis players who underwent arthroscopic hip surgery and to (2) compare outcomes between recreational and competitive tennis players. Our hypothesis was that both competitive and recreational tennis players would have improved PROs after hip arthroscopy and would return to tennis at similar rates.

\section{Methods}

\section{Patient selection criteria}

Data were prospectively collected and retrospectively reviewed for all patients who underwent primary hip arthroscopy in the setting of FAI or a labral tear between March 2009 and January 2014. Patients who met any of the following criteria were excluded from this study: patients over 60 years old, Tönnis osteoarthritis Grade > 1, Workers' Compensation claims, previous ipsilateral hip surgeries, or previous hip conditions such as Perthes, avascular necrosis, slipped capital femoral epiphysis, femoral head or acetabulum fractures. Patients in this study played tennis at the professional, collegiate, high school, organized amateur, or recreational level within one-year of surgery and intended to return to tennis following surgery. Patients who had preoperative and minimum five-year follow-up on the following outcome measures were included in this analysis: modified Harris Hip Score (mHHS), Non-Arthritic Hip Score (NAHS), Hip Outcome Score-Sport Specific Subscale (HOS-SSS), and visual analog scale (VAS) for pain.

All patients participated in the American Hip Institute Hip Preservation Registry. While the present study represents a unique analysis, data on some patients in this study has been reported in other studies $[11,12]$. All data collection received Institutional Review Board approval.

\section{Indications for surgery}

All surgical candidates were assessed with a detailed medical history, physical examination, and radiographic analysis. Patients were evaluated for FAI, acetabular version, dysplasia, and Tönnis grade for osteoarthritis using the supine, anteroposterior pelvis, false-profile, and Dunn-view $X$-ray views. In addition, magnetic resonance arthrography (MRA) was used to assess labral tears and cartilage damage. If patients had pain interfering with the activities of daily living for at least 3 months and failed to improve with conservative measures (rest, non-steroidal antiinflammatory drugs (NSAIDs), cortisone injections, and physical therapy), they were recommended for surgery.

\section{Surgical technique}

All surgeries were performed by a single surgeon (B.G.D.) with the patients placed in the supine position on a traction table with a well-padded perineal post $[13,14]$. The joint was accessed through the standard anterolateral and mid-anterior accessory portals. A capsulotomy was performed with a beaver blade. The intra-articular space was then evaluated using a diagnostic arthroscopy. The Seldes [15], acetabular labral articular disruption (ALAD) [16], and Domb and Villar Classification Systems [17] were 
used to assess the labrum, intra-articular cartilage, and ligamentum teres, respectively. An acetabuloplasty was performed to address pincer-type FAI and a femoroplasty was performed to address cam-type FAI [18-20]. Ligamentum teres (LT) tears were debrided [21]; fullthickness chondral defects were addressed with microfracture [22]; and iliopsoas impingement lesions or painful internal snapping were treated with iliopsoas fractional lengthening $[23,24]$. Labral tears were treated with repair, debridement, resection, or reconstruction depending on the integrity of the labrum [25]. The decision to release, repair, or plicate the capsule was dictated by the patient's Beightons score and acetabular coverage [26, 27].

\section{Rehabilitation}

Using a fitted X-Act ROM brace (DJO Global Vista, CA) and crutches, patients were instructed to use toe-touch weight bearing for 2 weeks. To restore strength and range of motion, physical therapy was initiated 1 day after surgery. Rehabilitation plans were adjusted for patients who underwent labral reconstruction, gluteus medius repair, or microfracture [28].

\section{Patient-reported outcomes}

Outcomes were assessed preoperatively and postoperatively at 3 months, 1-year, and annually thereafter using the following PROs: mHHS [29], NAHS [30], HOS-SSS [31], and VAS for pain [32]. Postoperative values for the International Hip Outcome Tool (iHOT-12) [33], the physical and mental components of the Veterans RAND 12-Item Health Survey (VR-12P and VR-12 M, respectively), and the physical and mental components of the Short Form 12 (SF-12P and SF-12 M, respectively) were also collected. Preoperative values for these scores were unavailable as they were not routinely collected for patients in this study period. Additionally, for mHHS and HOS-SSS, the number of patients achieving minimal clinically important difference (MCID) $(+8$ and +6 , respectively) and patient acceptable symptomatic state (PASS) ( $\geq 74$ and $\geq 75$, respectively) were calculated [34]. VAS was measured on a scale from 0 (no pain) to 10 (worst possible pain). Patient satisfaction was rated out of 10, with 10 signifying extreme satisfaction. Complications, secondary arthroscopies, and conversion to total hip arthroplasty (THA) were also reported.

\section{Sub-analysis}

A sub-analysis was performed to compare those who returned to tennis following surgery to those who were not able to return to play following surgery. An additional sun-analysis was performed to compare hips with severe cartilage damage (Acetabular Outerbridge grade $>2$ and/ or Femoral head Outerbridge grade $>2$ ) to those without severe cartilage damage. These analyses compared age, body-mass index (BMI), rate of RTS, and pre- and postoperative PROs.

\section{Statistical analysis}

All statistical analyses were completed using Microsoft Excel with the Real Statistics Add-In (Microsoft Corporation; Redmond, WA). Normality and equality of variances were assessed by the Shapiro-Wilk Test and Ftest, respectively. The two-tailed student's T-test assessed continuous parametric data. The Wilcoxon signed-Rank test was used as the non-parametric equivalent. Spearman's rank correlation coefficient was used to assess the correlation between physical exam findings and RTS ability. Categorical data was evaluated using the Chi-Square and Fisher's exact tests. A $P$-value of < 0.05 was considered statistically significant.

\section{Results}

\section{Patient demographics}

There were 28 patients (31 hips) that met the inclusion and exclusion criteria. Of these, 25 (89.3\%) patients (28 hips) had minimum five-year follow-up (mean: $72.8 \pm 13.9$ months). There were 3 professional, 3 collegiate, 2 high school, 2 organized amateur, and 18 recreational level tennis players. This patient cohort consisted of 14 (50.0\%) males and 14 (50.0\%) females. The mean age at surgery was $41.4 \pm 12.7$ years and the mean BMI was $25.1 \pm 3.9 \mathrm{~kg} / \mathrm{m}^{2}$. The demographics are summarized in Table 1.

\section{Intraoperative findings}

Intraoperative findings from the diagnostic arthroscopy are summarized in Table 2. All patients had a labral tear. There were 12 (42.9\%) Seldes Type 1, 4 (14.3\%) Seldes type II, and 12 (42.9\%) Seldes type I \& II labral tears. Cartilage integrity was assessed using the ALAD and

Table 1 Demographics

\begin{tabular}{ll}
\hline & Value \\
\hline Patients and hips included in study & 25 patients, 28 hips \\
Left & $10(35.7 \%)$ \\
Right & $18(64.3 \%)$ \\
Gender & \\
$\quad$ Male & $14(50.0 \%)$ \\
$\quad$ Female & $14(50.0 \%)$ \\
Age at surgery (years, mean, SD, range) & $41.4 \pm 12.7(14.5-70.0)$ \\
BMI (mean, SD, range) & $25.1 \pm 3.9(18.3-34.2)$ \\
Follow-up time (months, mean, SD, range) & $66.8 \pm 20.2(60.0-114.2)$ \\
Follow-up percentage & $90.32 \%$ \\
Flexion ${ }^{\circ}$ (mean, SD, range) & $116.3 \pm 14.8(85-140)$ \\
Internal Rotation ${ }^{\circ}$ (mean, SD, range) & $20.0 \pm 14.5(5-55)$ \\
External Rotation ${ }^{\circ}$ (mean, SD, range) & $42.5 \pm 13.6(15-70)$ \\
\hline BMI Body mass index, SD Standard deviation &
\end{tabular}

BMI Body mass index, SD Standard deviation 
Table 2 Intraoperative findings

\begin{tabular}{|c|c|}
\hline & $\mathrm{n}(\%)$ \\
\hline \multicolumn{2}{|l|}{ Seldes Tear Type } \\
\hline 0 & 0 \\
\hline 1 & $12(42.9 \%)$ \\
\hline 2 & $4(14.3 \%)$ \\
\hline $1 \& 2$ & $12(42.9 \%)$ \\
\hline \multicolumn{2}{|l|}{ ALAD } \\
\hline 0 & $1(3.6 \%)$ \\
\hline 1 & $3(10.7 \%)$ \\
\hline 2 & $10(35.7 \%)$ \\
\hline 3 & $10(35.7 \%)$ \\
\hline 4 & $4(14.3 \%)$ \\
\hline \multicolumn{2}{|l|}{ Outerbridge (Acetabular) } \\
\hline 0 & $0(0.0 \%)$ \\
\hline 1 & $3(10.7 \%)$ \\
\hline 2 & $10(35.7 \%)$ \\
\hline 3 & $5(17.9 \%)$ \\
\hline 4 & $10(35.7 \%)$ \\
\hline \multicolumn{2}{|c|}{ Outerbridge (Femoral Head) } \\
\hline 0 & $16(57.1 \%)$ \\
\hline 1 & $0(0.0 \%)$ \\
\hline 2 & $6(21.4 \%)$ \\
\hline 3 & $3(10.7 \%)$ \\
\hline 4 & $3(10.7 \%)$ \\
\hline \multicolumn{2}{|l|}{ LT Percentile Class (Domb) } \\
\hline $0-0 \%$ & $14(50.0 \%)$ \\
\hline $1-0 \%<50 \%$ & $7(25.0 \%)$ \\
\hline $2-50 \%<100 \%$ & $7(25.0 \%)$ \\
\hline $3-100 \%$ & $0(0.0 \%)$ \\
\hline \multicolumn{2}{|l|}{ LT Villar Class ${ }^{\mathrm{a}}$} \\
\hline 0 - No tear & $14(53.8 \%)$ \\
\hline 1 - Complete Rupture & $0(0 \%)$ \\
\hline 2 - Partial Tear & $9(34.6 \%)$ \\
\hline 3 - Degenerate Tear & $3(11.5 \%)$ \\
\hline
\end{tabular}

$A L A D$ Acetabular labral articular disruption, $L T$ Ligamentum teres anly data on 26 of 28 patients

Outerbridge classification systems. Twenty-four (85.7\%) hips were assigned an ALAD grade $\geq 2,25$ (89.3\%) hips were assigned an acetabular Outerbridge grade $\geq 2$, and 12 (42.9\%) hips were assigned a femoral head Outerbridge grade $\geq 2$. Fourteen $(50 \%)$ hips presented with LT tears.

\section{Arthroscopic procedures}

The intraoperative procedures are summarized in Table 3. The majority $(64.3 \%)$ of labral tears were repaired. The capsule was repaired or plicated in $12(42.9 \%)$ hips and released in 16 (57.1\%) hips. Twenty-five (89.3\%) hips
Table 3 Procedures

\begin{tabular}{ll}
\hline & $\mathrm{n}(\%)$ \\
\hline Labral treatment & $18(64.3 \%)$ \\
Repair & $8(28.6 \%)$ \\
Resection & $1(3.6 \%)$ \\
Reconstruction & $1(3.6 \%)$ \\
Capsular Treatment & \\
Repair/Plication & $12(42.9 \%)$ \\
Release & $16(57.1 \%)$ \\
Femoroplasty & $25(89.3 \%)$ \\
Acetabuloplasty & $21(75.0 \%)$ \\
Iliopsoas fractional lengthening & $10(35.7 \%)$ \\
Ligamentum teres debridement & $12(42.9 \%)$ \\
Removal of loose body & $7(25.0 \%)$ \\
Synovectomy & $8(28.6 \%)$ \\
Trochanteric bursectomy & $6(21.4 \%)$ \\
Gluteus medius/minimus repair & $5(17.9 \%)$ \\
Acetabular microfracture & $6(21.4 \%)$ \\
Femoral head microfracture & $2(7.1 \%)$ \\
Acetabular chondroplasty & $6(21.4 \%)$ \\
Femoral head chondroplasty & $4(14.3 \%)$ \\
\hline
\end{tabular}

underwent a femoroplasty and 21 (75.0\%) hips underwent an acetabuloplasty. Of the 14 LT tears, 12 (85.7\%) hips were treated via debridement. Additionally, 10 (35.7\%) hips underwent an iliopsoas fractional lengthening.

\section{Outcomes at latest follow-up}

Preoperative and minimum five-year PROs, VAS, and patient satisfaction are detailed in Table 4. All mean scores improved significantly at latest follow-up: mHHS improved from 67.0 to $86.7(P<0.001)$, NAHS improved from 65.9 to $87.2(P<0.001)$, HOS-SSS improved from 50.0 to $77.9(P=0.009)$, and VAS improved from 5.4 to $1.8(P<0.001)$. For mHHS, $66.7 \%$ of patients achieved MCID and 83.3\% achieved PASS. For HOSSSS, $63.6 \%$ achieved MCID and 58.3\% achieved PASS. Mean patient satisfaction with surgery was $8 / 10$. There was a $75.0 \%$ RTS rate in this tennis population, with 15 (71.4\%) playing at the same or a higher level postoperatively. Although not statistically significant, patients who played tennis at a competitive level (professional, college, high school, or organized amateur) experienced greater improvements in outcome scores compared to patients who played tennis recreationally (Table 5). The nature of our data suggest that competitive athletes may achieve higher PROs at minimum 5-year follow-up compared to the recreational group, particularly for HOS-SSS and VAS (Table 5). The mean age of the two groups were 
Table 4 PROs

\begin{tabular}{lllr}
\hline & Preoperative & Minimum Five-Year Follow-Up & \multicolumn{1}{c}{$\boldsymbol{P}$-Value } \\
\hline mHHS (mean, SD) & $67.0 \pm 17.2$ & $86.7 \pm 16.4$ & $\mathbf{0 . 0 0 1}$ \\
NAHS (mean, SD) & $65.9 \pm 17.3$ & $87.2 \pm 17.4$ & $\mathbf{0 . 0 0 9}$ \\
HOS-SSS (mean, SD) & $50.0 \pm 25.0$ & $77.9 \pm 25.2$ & $80.7 \pm 26.6$ \\
IHOT (mean, SD) & & $58.8 \pm 3.0$ \\
SF-12 Mental (mean, SD) & & $51.9 \pm 8.3$ \\
SF-12 Physical (mean, SD) & & $63.4 \pm 3.5$ \\
VR-12 Mental (mean, SD) & & $52.9 \pm 8.0$ \\
VR-12 Physical (mean, SD) & & $1.8 \pm 2.5$ \\
VAS (mean, SD) & $5.4 \pm 2.3$ & $8.0 \pm 3.2$ & $<\mathbf{0 . 0 0 1}$ \\
Patient Satisfaction (mean, SD) & &
\end{tabular}

\section{Bold text: statistically significant}

PROs Patient reported outcomes, mHHS Modified Harris Hip Score, NAHS Non-Arthritic Hip Score, HOS-SSS Hip Outcome Score-Sport Specific Subscale, VAS Visual analog scale, iHOT-12 International Hip Outcome Tool, VR-12P and VR-12 M The physical and mental components of the Veterans RAND 12-Item Health Survey, respectively, SF-12P and SF-12 $M$, respectively The physical and mental components of the Short Form 12, respectively

Table 5 Comparison of PROs between high level and recreational tennis players

\begin{tabular}{|c|c|c|c|}
\hline & Competitive $(\boldsymbol{n}=12)$ & Recreational $(\boldsymbol{n}=18)$ & $P$-value \\
\hline \multicolumn{4}{|l|}{ mHHS (mean, SD) } \\
\hline Pre & $69.7 \pm 12.6$ & $65.9 \pm 18.9$ & 0.607 \\
\hline Latest & $95.6 \pm 8.3$ & $83.0 \pm 17.7$ & 0.075 \\
\hline Pre-Post P-Value & 0.016 & 0.009 & \\
\hline$\Delta$ & $25.8 \pm 16.4$ & $17.5 \pm 25.2$ & 0.433 \\
\hline \multicolumn{4}{|l|}{ NAHS (mean, SD) } \\
\hline Pre & $72.0 \pm 16.2$ & $63.5 \pm 17.5$ & 0.249 \\
\hline Latest & $94.6 \pm 10.4$ & $84.2 \pm 19.0$ & 0.130 \\
\hline Pre-Post P-Value & 0.047 & 0.002 & \\
\hline$\Delta$ & $20.4 \pm 18.0$ & $20.3 \pm 24.2$ & 0.991 \\
\hline \multicolumn{4}{|l|}{ HOS-SSS (mean, SD) } \\
\hline Pre & $54.9 \pm 25.0$ & $48.0 \pm 25.4$ & 0.521 \\
\hline Latest & $91.7 \pm 22.0$ & $71.9 \pm 24.7$ & 0.027 \\
\hline Pre-Post P-Value & 0.063 & 0.058 & \\
\hline$\Delta$ & $34.9 \pm 36.4$ & $20.8 \pm 33.7$ & 0.381 \\
\hline \multicolumn{4}{|l|}{ VAS (mean, SD) } \\
\hline Pre & $5.4 \pm 1.8$ & $5.4 \pm 2.5$ & 0.98 \\
\hline Latest & $0.4 \pm 0.8$ & $2.4 \pm 2.8$ & 0.041 \\
\hline Pre-Post P-Value & 0.016 & $<0.001$ & \\
\hline$\Delta$ & $-4.8 \pm 2.0$ & $-3.2 \pm 2.5$ & 0.146 \\
\hline IHOT (mean, SD) & $91.4 \pm 18.5$ & $76.0 \pm 28.6$ & 0.062 \\
\hline SF-12 Mental (mean, SD) & $59.0 \pm 3.2$ & $58.8 \pm 3.0$ & 0.535 \\
\hline SF-12 Physical (mean, SD) & $55.5 \pm 2.4$ & $50.4 \pm 9.5$ & 0.058 \\
\hline VR-12 Mental (mean, SD) & $64.4 \pm 2.7$ & $63.0 \pm 3.8$ & 0.535 \\
\hline VR-12 Physical (mean, SD) & $56.3 \pm 2.1$ & $51.4 \pm 9.1$ & 0.058 \\
\hline Patient Satisfaction (mean, SD) & $8.4 \pm 2.9$ & $7.8 \pm 3.4$ & 0.757 \\
\hline
\end{tabular}

Bold text: statistically significant

PROs Patient reported outcomes, $\triangle$ Delta, mHHS Modified Harris Hip Score, NAHS Non-Arthritic Hip Score, HOS-SSS Hip Outcome Score-Sport Specific Subscale, VAS Visual analog scale, iHOT-12 International Hip Outcome Tool, VR-12P and VR-12 M The physical and mental components of the Veterans RAND 12-Item Health Survey, respectively, SF-12P and SF-12 M, respectively The physical and mental components of the Short Form 12, respectively 
not statistically different at 34.9 years in the competitive group and 44.0 years in the recreational group $(P=$ 0.099).

\section{Sub-analysis on return to sport}

Both competitive and recreational tennis players returned to play at similar rates $(P=0.233)$. There seemed to be a pattern in patients who returned to tennis having higher preoperative mHHS, NAHS, and HOS-SSS scores; however, there was no significant differences $(P>0.05)$ between the RTS and did not RTS groups (Fig. 1). Although only statistically significant for NAHS and HOS-SSS $(P=0.048$ and 0.018 , respectively), there was a similar trend suggesting patients who were able to return to tennis at latest follow-up had superior PROs at minimum 5-year follow-up compared to patients who were not able to return to tennis (Fig. 2). In addition, there was no significant differences $(P>0.05)$ in age or BMI between the RTS and did not RTS groups. With regard to physical examination findings, the relationship indicated a negative correlation between flexion, internal rotation, external rotation and RTS ability, however these were not statistically significant $(P>0.05)$.

\section{Sub-analysis on cartilage damage}

The intraoperative findings suggested 17 cases had an acetabular Outerbridge or femoral head Outerbridge grade $>2$ (11 acetabular Outerbridge $>2,2$ femoral head
Outerbridge $>2$, and 4 with both grades $>2$ ). Demographic factors including age at surgery and BMI were not statistically different between the hips with severe cartilage damage and hips without severe cartilage damage $(P=0.112$ and 0.052 , respectively). Similarly, both groups returned to tennis at similar rates $(P=0.933)$. The group with severe cartilage damage returned to tennis at a $76.4 \%$ rate and cases without severe cartilage damage returned at a $72.7 \%$ rate. Pre- and postoperative PROs were compared between the two groups. No statistical differences were found between mHHS, NAHS, or HOS-SSS preoperatively or postoperatively as shown in Figs. 3 and $4(P>0.05)$.

Of the 17 cases with severe cartilage damage, 8 (47.1\%) required follow-up treatment including 1 revision arthroscopy, 2 THA, 4 platelet-rich plasma injections, and 1 lidocaine and depo-Medrol injection to the piriformis. The need for a secondary surgery was similar between groups $(P>0.999)$.

\section{Complications, secondary arthroscopies, and conversions to total hip arthroplasty}

Of the entire cohort, one (3.6\%) patient had follow-up complications. This patient reported piriformis syndrome and bursitis at 6-year follow-up. One (3.6\%) hip required a secondary arthroscopy at 9.9 months and four (14.3\%) hips converted to a THA at mean of 31.3 months following the index surgery.

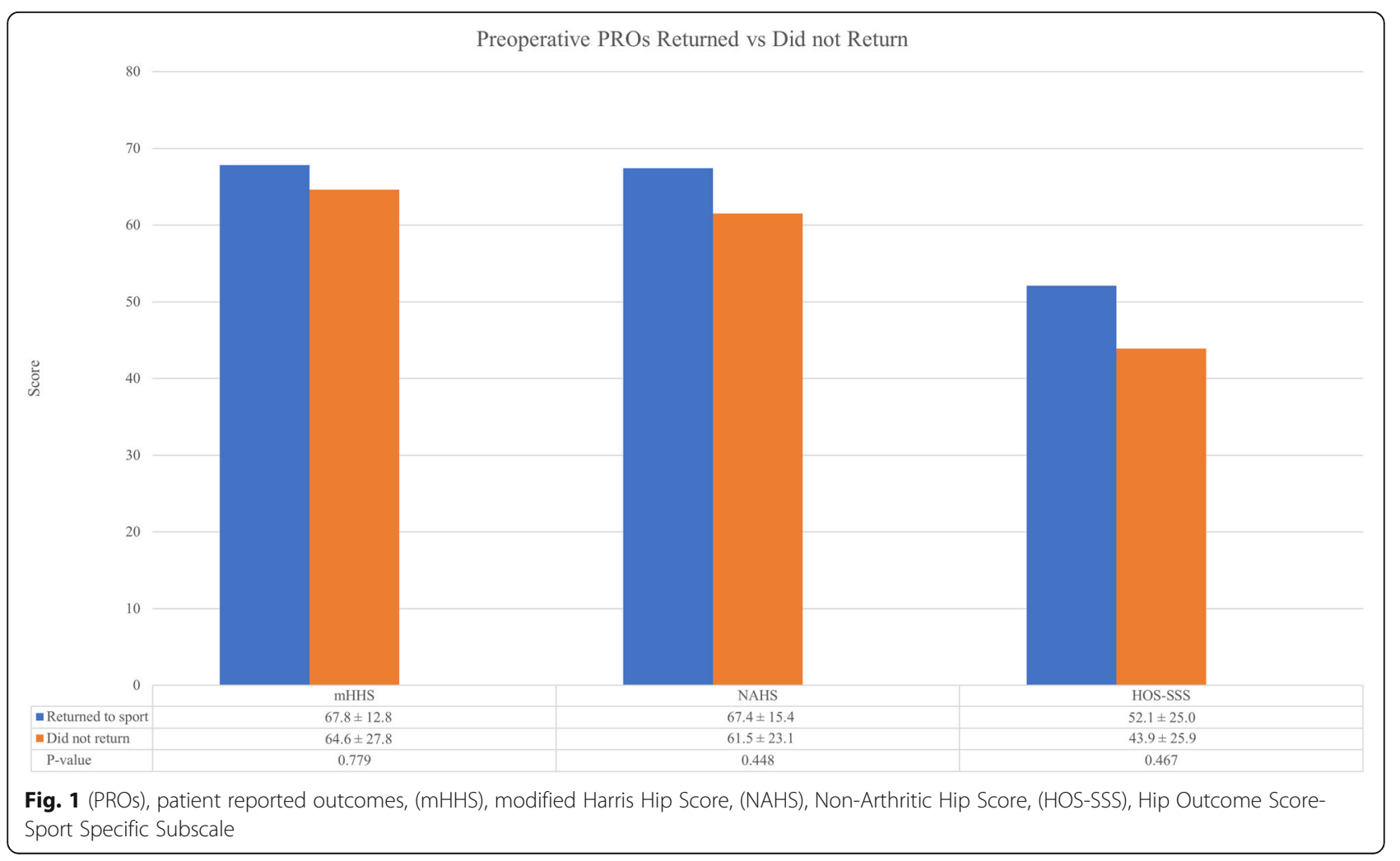



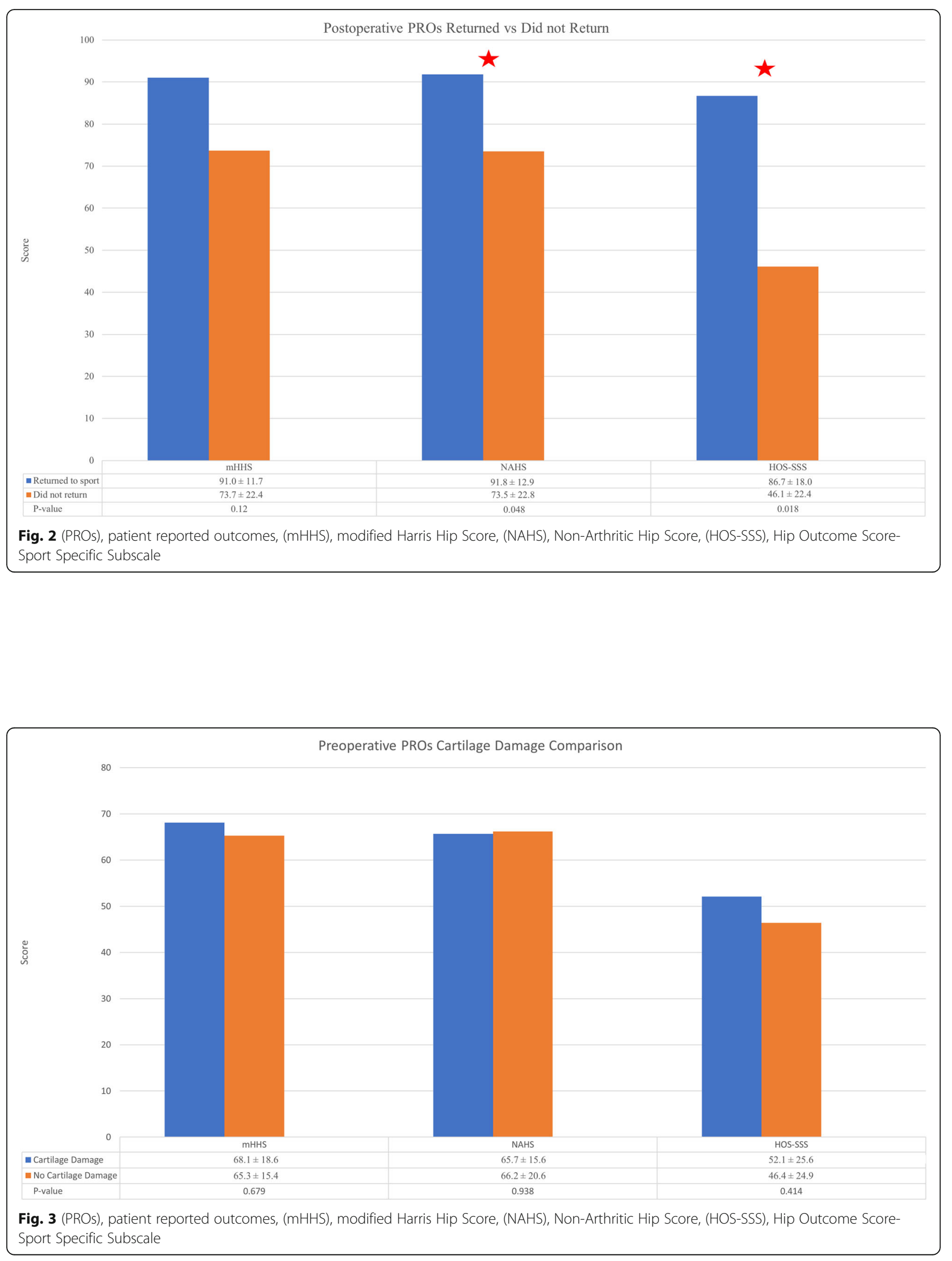


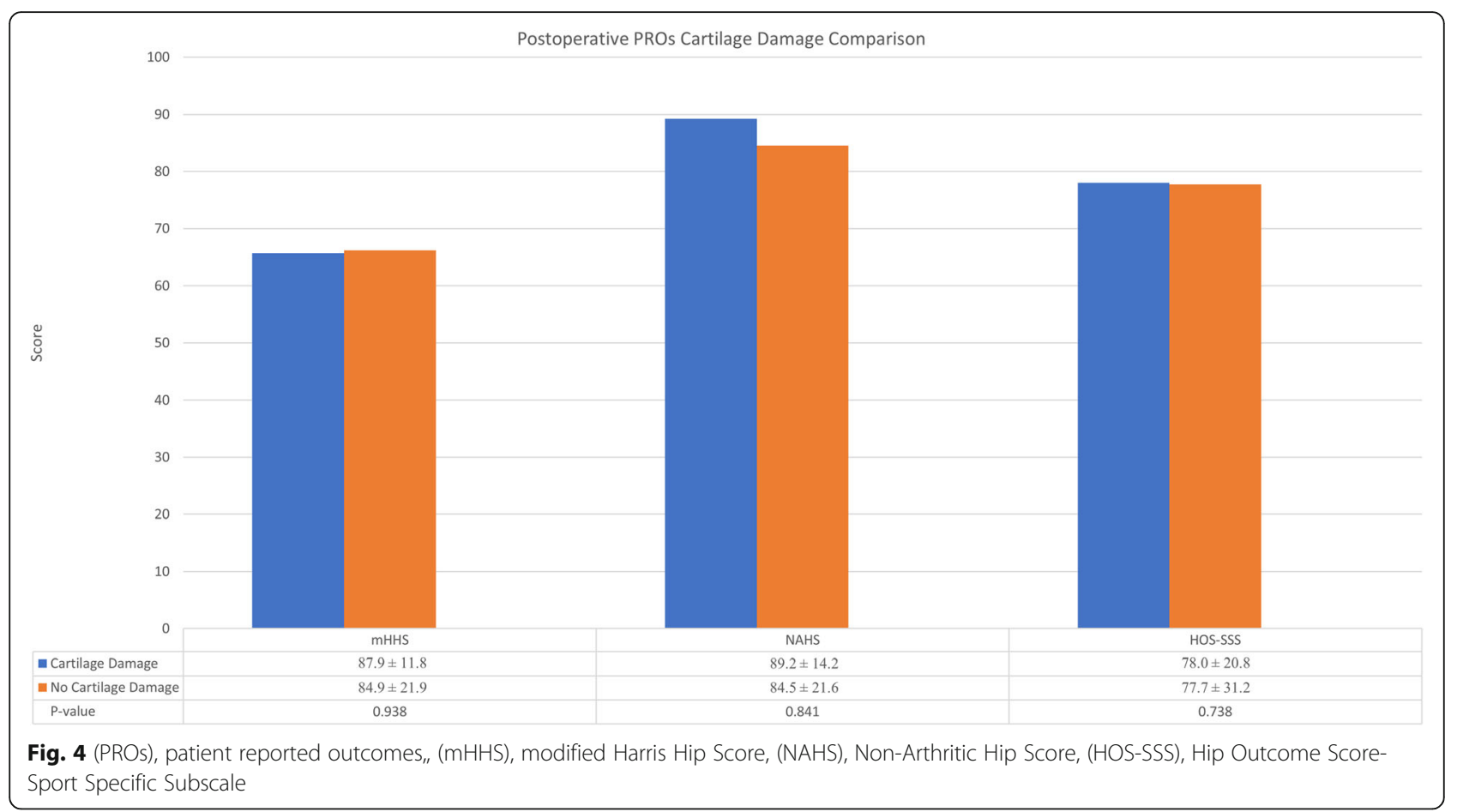

\section{Discussion}

This study showed that PROs significantly improved from pre-operative to latest follow-up: mHHS from 67.0 to 86.7 NAHS from 65.9 to 87.2 , HOS-SSS from 50.0 to 77.9, and VAS from 5.4 to 1.8. As expected, tennis players who were able to RTS had higher mHHS, NAHS, and HOS-SSS scores at latest follow-up, although only significant for NAHS and HOS-SSS. There were no significant differences in pre- to post-operative changes in PROs between competitive and recreational athletes. However, HOS-SSS and VAS were statistically better at latest follow-up between competitive athletes and recreational athletes. Additionally, the sub-analysis comparing athletes with severe cartilage damage to those without severe cartilage damage showed no differences in RTS rate, preoperative PROs, or postoperative PROs.

Previous studies have investigated functional outcomes in an athletic population following hip arthroscopy. Nho et al. reported an improvement in mHHS of 66.8 to 88.5 [35], a delta similar to the present study. Furthermore, in a cohort of 53 athletic patients at average 2.4 year followup, Brunner et al. reported comparable postoperative scores for NAHS as found in this study (86.7 versus 87.2 ) [36]. These results extend to professional athletes, as studies have shown high $(>80 \%)$ rates of return to play after hip arthroscopy. Philippon et al. reported a 93\% RTS rate in 45 professional athletes [37]; Menge et al. reported a 85.7\% RTS rate [38]; and Bokyin et al. reported a $85.7 \%$ RTS rate in patients who underwent hip arthroscopy with labral reconstruction [39]. Furthermore, literature has also reported similar RTS rates in athletic patients who underwent open surgery for FAI [40].

To our knowledge, there has not been a previous study to report PROs and RTS on tennis players who underwent hip arthroscopy. In the present study, there were 7 (25.0\%) tennis players (1 high school, 1 organized amateur, and 5 recreational) who were not playing tennis at latest follow-up. Out of the 8 competitive tennis players, $7(87.5 \%)$ were able to RTS. However, our cohort is small and is also likely affected by the small number of professional tennis players.

In the present study, the difference in return to play between competitive and recreational tennis players was not statistically significant $(P=0.233)$. However, this result must be interpreted cautiously due to the small number of professional athletes analyzed in this study. Professional athletes have been shown to RTS at higher rates than recreational athletes $[35,38]$. Rate of RTS appears to be highly influenced by factors such as self-motivation, aging, pain, encouragement, and adaptation to physical limitations $[41,42]$. These factors as well as monetary incentives and the limited window to play at the elite level motivate professional athletes to return to play. In a recent systematic review, Casartelli et al. reported a $87 \%$ RTS rate in both competitive and recreational athletes [10].

Tennis is considered a physically demanding sport, with more cutting and pivoting motions than biking or swimming [2]. Interestingly, tennis players with greater internal rotation and greater external rotation were less likely to RTS. Studies have evaluated the relationship between 
general joint hypermobility and athletic outcomes following hip arthroscopy. Weber et al. found that capsular plication in athletes may actually impair RTS by limiting the external rotation necessary for complex sports [43]. On the contrary, studies have also shown no significant relationship between Beightons scores and functional outcomes following hip arthroscopy [44, 45]. It seems that patients with greater internal or external rotation have increased joint instability that may preclude them from returning to their sport.

\section{Strengths}

Strengths of this study include the use of multiple validated functional hip outcome scores such as mHHS, NAHS, and HOS-SSS, that were designed specifically to detect outcomes in active patients with non-arthritic hips. Moreover, with this multiple PROs use, the authors tried to limit the ceiling effect of a single PRO. Furthermore, this is one of the only studies to report PROs in a mixed group of tennis players at minimum five-year follow up. Finally, as statistical significance does not equate clinical significance, the proportion of patients who achieved the MCID and PASS for MHHS and HOS-SSS was also provided [34, 46].

\section{Limitations}

Limitations include the non-randomized and retrospective design of the present study. Further, heterogeneity among the arthroscopic procedures performed and competitive level must be acknowledged and could influence the findings of the study. The study is also retrospective in nature, which introduces an inherent bias; nevertheless, this bias may be limited by prospective data collection. The present study included minimum five-year follow-up, albeit longer follow is needed to determine durability of the results. In addition, all procedures were performed by a single surgeon, which may limit the generalizability of the results. Although this is one of the few case-series reporting mid-term outcomes in tennis players who underwent hip arthroscopy, the sample size in relatively small and limits the generalizability of the results. Furthermore, capsular and labral management has evolved in the recent years and in consequence, patients who underwent labral debridement and capsular release in the ongoing study would currently be treated with labral restoration techniques such labral reconstruction or labral augmentation, and capsular plication $[25,26,47-49]$.

\section{Conclusion}

Regardless of the level of participation, tennis players who underwent hip arthroscopic surgery reported statistically significant PRO improvements. A favorable RTS was also achieved by players with a continued interest in playing. The data here may be useful in counseling tennis players of various levels who are considering arthroscopic treatment of a hip injury.

\section{Abbreviations}

PROs: Patient reported outcomes; FAl: Femoracetabular Impingement; RTS: Return to sport; mHHS: Modified Harris Hip Score; NAHS: Non-arthritic Hip Score; HOS-SSS: Hip Outcome Score - Sport Specific Subscale;

VAS: Visual analog scale; PASS: Patient Accepted Symptomatic State; MCID: Minimal clinically important difference; THA: Total hip arthroplasty; TIA: Tennis Industry Association; MRA: Magnetic Resonance Angiogram; NSAIDs: Non-steroidal anti-inflammatory drugs; BMI: Body Mass Index; ALAD: Acetabular labral articular disruption; LT: Ligamentum Teres;

SD: Standard deviation; $\triangle$ : Delta; iHOT-12: International Hip Outcome Tool; VR-12P: Physical component of the Veterans RAND 12-Item Health Survey; VR-12 M: Mental component of the Veterans RAND 12-Item Health Survey; SF-12P: Physical component of the Short Form 12; SF-12 M: Mental components of the Short Form 12

\section{Acknowledgements}

Not applicable.

\section{Authors' contributions}

DRM participated in the data collection/analysis and writing of the manuscript; MJY participated in the data collection/analysis and writing of the manuscript; PJR participated in the data collection and data analysis; JS participated in the data collection and data analysis; $A C L$ participated in the revisions of the manuscript; $B G D$ participated in the revisions of the manuscript. The author(s) read and approved the final manuscript.

\section{Funding}

Not applicable.

\section{Availability of data and materials}

No additional data is available.

\section{Ethics approval and consent to participate}

All patients participated in the American Hip Preservation Registry. While the present study represents a unique analysis, data on some patients in this study has been reported in other studies. All data collection received Advocate Health Care Institutional Review Board approval.

\section{Consent for publication \\ Not applicable.}

\section{Competing interests}

Dr. Domb reports grants and other from American Orthopedic Foundation, during the conduct of the study; personal fees from Adventist Hinsdale Hospital, personal fees and non-financial support from Amplitude, grants, personal fees and non-financial support from Arthrex, personal fees and nonfinancial support from DJO Global, grants from Kaufman Foundation, grants, personal fees and non-financial support from Medacta, grants, personal fees, non-financial support and other from Pacira Pharmaceuticals, grants, personal fees, non-financial support and other from Stryker, grants from Breg, personal fees from Orthomerica, grants, personal fees, non-financial support and other from Mako Surgical Corp, grants and non-financial support from Medwest Associates, grants from ATI Physical Therapy, grants, personal fees and nonfinancial support from St. Alexius Medical Center, grants from Ossur, outside the submitted work; In addition, Dr. Domb has a patent 8920497 - Method and instrumentation for acetabular labrum reconstruction with royalties paid to Arthrex, a patent 8708941 - Adjustable multi-component hip orthosis with royalties paid to Orthomerica and DJO Global, and a patent 9737292 - Knotless suture anchors and methods of tissue repair with royalties paid to Arthrex and Dr. Domb is the Medical Director of Hip Preservation at St. Alexius Medical Center, a board member for the American Hip Institute Research Foundation, AANA Learning Center Committee, the Journal of Hip Preservation Surgery, the Journal of Arthroscopy; has had ownership interests in the American Hip Institute, Hinsdale Orthopedic Associates, Hinsdale Orthopedic Imaging, SCD\#3, North Shore Surgical Suites, and Munster Specialty Surgery Center. 
Dr. Lall reports grants, personal fees and non-financial support from Arthrex non-financial support from Iroko, non-financial support from Medwest, nonfinancial support from Smith \& Nephew, grants and non-financial support from Stryker, non-financial support from Vericel, non-financial support from Zimmer Biomet, personal fees from Graymont Medical, outside the submitted work; and Dr. Lall is the Medical Director of Hip Preservation at St. Alexius Medical Center.

Dr. Maldonado reports non-financial support from Arthrex, non-financial support from Stryker, non-financial support from Smith \& Nephew, non-financial support from Ossur, outside the submitted work; and Dr. Maldonado is an editorial board member of the Journal of Arthroscopy.

Dr. Meghpara reports non-financial support from Smith \& Nephew, nonfinancial support from Stryker, non-financial support from Arthrex, outside the submitted work.

Dr. Shapira reports non-financial support from Arthrex, non-financial support from Stryker, non-financial support from Smith \& Nephew, non-financial support from Ossur, outside the submitted work.

Dr. Rosinsky reports non-financial support from Arthrex, non-financial support from Stryker, non-financial support from Smith \& Nephew, non-financial support from Ossur, outside the submitted work.

All other authors have no competing interests.

\section{Author details}

'American Hip Institute Research Foundation, Des Plaines, IL 60018, USA. ${ }^{2}$ AMITA Health St. Alexius Medical Center, Hoffman Estates, IL 60169, USA. ${ }^{3}$ American Hip Institute, 999 E Touhy Ave, Suite 450, Des Plaines, IL 60018, USA.

Received: 6 September 2019 Accepted: 16 June 2020

Published online: 23 June 2020

\section{References}

1. Pluim BM, Miller S, Dines D, Renström PAHF, Windler G, Norris B, et al. Sport science and medicine in tennis. Br J Sports Med. 2007:41(11):703.

2. Abrams GD, Renstrom PA, Safran MR. Epidemiology of musculoskeleta injury in the tennis player. Br J Sports Med. 2012;46(7):492.

3. Byrd JWT, Jones KS. Arthroscopic management of femoroacetabular impingement in athletes. Am J Sports Med. 2011;39(Suppl):7S-13S.

4. Byrd JWT, Jones KS, Gwathmey FW. Femoroacetabular impingement in adolescent athletes outcomes of arthroscopic management. Am J Sports Med. 2016:44(8):2106-11.

5. Levy DM, Kuhns BD, Frank RM, Grzybowski JS, Campbell KA, Brown S, et al. High rate of return to running for athletes after hip arthroscopy for the treatment of Femoroacetabular impingement and capsular plication. Am J Sports Med. 2017;45(1):127-34

6. McDonald JE, Herzog MM, Philippon MJ. Return to play after hip arthroscopy with microfracture in elite athletes. Arthroscopy. 2013;29(2): 330-5.

7. Byrd JWT. Femoroacetabular impingement in athletes current concepts. Am J Sports Med. 2014:42(3):737-51.

8. Byrd JWT, Jones KS. Prospective analysis of hip arthroscopy with 10-year followup. Clin Orthop Relat Res. 2010:468(3):741-6.

9. Weber AE, Kuhns BD, Cvetanovich GL, Grzybowski JS, Salata MJ, Nho SJ. Amateur and recreational athletes return to sport at a high rate following hip arthroscopy for Femoroacetabular impingement. Arthroscopy. 2017; 33(4):748-55.

10. Casartelli NC, Leunig M, Maffiuletti NA, Bizzini M. Return to sport after hip surgery for femoroacetabular impingement: a systematic review. Br J Sports Med. 2015;49(12):819-24.

11. Rosinsky PJ, Kyin C, Lall AC, Shapira J, Maldonado DR, Domb BG. Rate of return to sport and functional outcomes after bilateral hip arthroscopy in high-level athletes. Am J Sports Med. 2019. https://doi.org/10.1177/ 0363546519885354.

12. Perets I, Craig MJ, Mu BH, Maldonado DR, Litrenta JM, Domb BG. Midterm outcomes and return to sports among athletes undergoing hip arthroscopy. Am J Sports Med. 2018:46(7):1661-7.

13. Maldonado DR, Chen JW, Walker-Santiago R, Rosinsky PJ, Shapira J, Lall AC, et al. Forget the greater trochanter! Hip joint access with the 12 o'clock portal in hip arthroscopy. Arthrosc Tech. 2019;8(6):e575-84.

14. Lall AC, Saadat AA, Battaglia MR, Maldonado DR, Perets I, Domb BG. Perineal pressure during hip arthroscopy is reduced by use of Trendelenburg: a prospective study with randomized order of positioning. Clin Orthop Relat Res.2019;477(8):1858-9.

15. Seldes RM, Tan V, Hunt J, Katz M, Winiarsky R, Fitzgerald RH. Anatomy, histologic features, and vascularity of the adult acetabular labrum. Clin Orthop Relat Res. 2001;382:232-40.

16. Callaghan JJ, Rosenberg AG, Rubash HE. The adult hip. Philadelphia: Lippincott Williams \& Wilkins; 1998. p. 868.

17. Botser IB, Martin DE, Stout CE, Domb BG. Tears of the Ligamentum Teres: prevalence in hip arthroscopy using 2 classification systems. Am J Sports Med. 2011;39(1_suppl):117-25.

18. Redmond JM, El Bitar YF, Gupta A, Stake CE, Vemula SP, Domb BG. Arthroscopic acetabuloplasty and labral refixation without labral detachment. Am J Sports Med. 2015:43(1):105-12.

19. Ortiz-Declet V, Mu B, Chen AW, Litrenta J, Yuen LC, Rabe SM, et al. The "bird's eye" and "upper deck" views in hip arthroscopy: powerful arthroscopic perspectives for acetabuloplasty. Arthrosc Tech. 2018;7(1):e13-6.

20. Mansor Y, Perets I, Close MR, Mu BH, Domb BG. In search of the spherical femoroplasty: cam overresection leads to inferior functional scores before and after revision hip arthroscopic surgery. Am J Sports Med. 2018;46(9): 2061-71.

21. Maldonado DR, Laseter JR, Perets I, Ortiz-Declet V, Chen AW, Lall AC, et al. The effect of complete tearing of the Ligamentum Teres in patients undergoing primary hip arthroscopy for femoroacetabular impingement and labral tears: a match-controlled study. Arthroscopy. 2019;35(1):80-8.

22. Domb BG, Rybalko D, Mu B, Litrenta J, Chen AW, Perets I. Acetabular microfracture in hip arthroscopy: clinical outcomes with minimum 5-year follow-up. Hip Int. 2018. https://doi.org/10.1177/1120700018760263.

23. Maldonado DR, Krych AJ, Levy BA, Hartigan DE, Laseter JR, Domb BG. Does \|liopsoas lengthening adversely affect clinical outcomes after hip arthroscopy? A multicenter comparative study. Am J Sports Med. 2018; 46(11):2624-31.

24. Maldonado DR, Lall AC, Battaglia MR, Laseter JR, Chen JW, Domb BG. Arthroscopic lliopsoas fractional lengthening. JBJS Essent Surg Tech. 2018;8(4):e30.

25. Domb BG, Hartigan DE, Perets I. Decision making for labral treatment in the hip: repair Versus Débridement versus reconstruction. J Am Acad Orthop Surg. 2017;25(3):e53-62.

26. Maldonado DR, Perets I, Mu BH, Ortiz-Declet V, Chen AW, Lall AC, et al. Arthroscopic capsular plication in patients with labral tears and borderline dysplasia of the hip: analysis of risk factors for failure. Am J Sports Med. 2018;46(14):3446-53.

27. Saadat AA, Lall AC, Battaglia MR, Mohr MR, Maldonado DR, Domb BG. Prevalence of generalized ligamentous laxity in patients undergoing hip arthroscopy: a prospective study of patients' clinical presentation, physical examination, intraoperative findings, and surgical procedures. Am J Sports Med. 2019:47(4):885-93.

28. Domb BG, Sgroi TA, VanDevender JC. Physical therapy protocol after hip arthroscopy: clinical guidelines supported by 2-year outcomes. Sports Health. 2016;8(4):347-54.

29. Aprato A, Jayasekera N, Villar RN. Does the modified Harris hip score reflect patient satisfaction after hip arthroscopy? Am J Sports Med. 2012;40(11): 2557-60.

30. Christensen CP, Althausen PL, Mittleman MA, Lee J, McCarthy JC. The nonarthritic hip score: reliable and validated. Clin Orthop Relat Res. 2003; 406:75-83.

31. Martin RL, Philippon MJ. Evidence of validity for the hip outcome score in hip arthroscopy. Arthroscopy. 2007;23(8):822-6.

32. Chandrasekaran S, Gui C, Walsh JP, Lodhia P, Suarez-Ahedo C, Domb BG Correlation between changes in visual analog scale and patient-reported outcome scores and patient satisfaction after hip arthroscopic surgery. Orthop J Sports Med. 2017;5(9) Available from: https://www.ncbi.nlm.nih. gov/pmc/articles/PMC5600309/. Cited 20 Jun 2019.

33. Griffin DR, Parsons N, Mohtadi NGH, Safran MR. Multicenter arthroscopy of the hip outcomes research network. A short version of the international hip outcome tool (iHOT-12) for use in routine clinical practice. Arthroscopy. 2012;28(5):611-6 quiz 616-8.

34. Levy DM, Kuhns BD, Chahal J, Philippon MJ, Kelly BT, Nho SJ. Hip arthroscopy outcomes with respect to patient acceptable symptomatic state and minimal clinically important difference. Arthroscopy. 2016;32(9):1877-86.

35. Nho SJ, Magennis EM, Singh CK, Kelly BT. Outcomes after the arthroscopic treatment of femoroacetabular impingement in a mixed group of high-level athletes. Am J Sports Med. 2011;39(Suppl):14S-9S. 
36. Brunner A, Horisberger M, Herzog RF. Sports and recreation activity of patients with femoroacetabular impingement before and after arthroscopic osteoplasty. Am J Sports Med. 2009;37(5):917-22.

37. Philippon M, Schenker M, Briggs K, Kuppersmith D. Femoroacetabular impingement in 45 professional athletes: associated pathologies and return to sport following arthroscopic decompression. Knee Surg Sports Traumatol Arthrosc. 2007;15(7):908-14.

38. Menge TJ, Bhatia S, McNamara SC, Briggs KK, Philippon MJ.

Femoroacetabular impingement in professional football players: return to play and predictors of career length after hip arthroscopy. Am J Sports Med. 2017:45(8):1740-4.

39. Boykin RE, Patterson D, Briggs KK, Dee A, Philippon MJ. Results of arthroscopic labral reconstruction of the hip in elite athletes. Am J Sports Med. 2013:41(10):2296-301.

40. Naal FD, Miozzari HH, Wyss TF, Nötzli HP. Surgical hip dislocation for the treatment of femoroacetabular impingement in high-level athletes. Am J Sports Med. 2011;39(3):544-50.

41. Domb BG, Dunne KF, Martin TJ, Gui C, Finch NA, Vemula SP, et al. Patient reported outcomes for patients who returned to sport compared with those who did not after hip arthroscopy: minimum 2-year follow-up. J Hip Preserv Surg. 2016;3(2):124-31.

42. Tjong VK, Cogan CJ, Riederman BD, Terry MA. A qualitative assessment of return to sport after hip arthroscopy for femoroacetabular impingement. Orthop J Sports Med. 2016;4(11) Available from: http://www.ncbi.nlm.nih. gov/pmc/articles/PMC5117156/. Cited 7 Dec 2016.

43. Weber AE, Bedi A, Tibor LM, Zaltz I, Larson CM. The Hyperflexible hip: managing hip pain in the dancer and gymnast. Sports Health. 2015;7(4): 346-58.

44. Naal FD, Müller A, Varghese VD, Wellauer V, Impellizzeri FM, Leunig M. Outcome of hip impingement surgery: does generalized joint hypermobility matter? Am J Sports Med. 2017;45(6):1309-14.

45. Pontiff M, Ithurburn MP, Ellis T, Cenkus K, Stasi SD. Pre- and post-operative self-reported function and quality of life in women with and without generalized joint laxity undergoing hip arthroscopy for femoroacetabular impingement. Int J Sports Phys Ther. 2016;11(3):378-87.

46. Harris JD, Brand JC, Cote MP, Faucett SC, Dhawan A. Research pearls: the significance of statistics and perils of pooling. Part 1: clinical versus statistical significance. Arthroscopy. 2017;33(6):1102-12.

47. Domb BG, Battaglia MR, Perets I, Lall AC, Chen AW, Ortiz-Declet V, et al. Minimum 5-year outcomes of arthroscopic hip labral reconstruction with nested matched-pair benchmarking against a labral repair control group. Am J Sports Med. 2019;47(9):2045-55.

48. Ortiz-Declet V, Mu B, Chen AW, Litrenta J, Perets I, Yuen LC, et al. Should the capsule be repaired or plicated after hip arthroscopy for labral tears associated with femoroacetabular impingement or instability? A systematic review. Arthroscopy. 2018:34(1):303-18.

49. Philippon MJ, Bolia IK, Locks R, Briggs KK. Labral preservation: outcomes following labrum augmentation versus labrum reconstruction. Arthroscopy. 2018;34(9):2604-11.

\section{Publisher's Note}

Springer Nature remains neutral with regard to jurisdictional claims in published maps and institutional affiliations.

Ready to submit your research? Choose BMC and benefit from:

- fast, convenient online submission

- thorough peer review by experienced researchers in your field

- rapid publication on acceptance

- support for research data, including large and complex data types

- gold Open Access which fosters wider collaboration and increased citations

- maximum visibility for your research: over $100 \mathrm{M}$ website views per year

At $\mathrm{BMC}$, research is always in progress.

Learn more biomedcentral.com/submissions 